\title{
Predictability of prototype flash flood events in the Western Mediterranean under uncertainties of the precursor upper-level disturbance
}

\author{
R. Romero, A. Martín, V. Homar, S. Alonso, and C. Ramis \\ Meteorology Group, Departament de Física, Universitat de les Illes Balears, Palma de Mallorca, Spain \\ Received: 7 October 2005 - Revised: 14 December 2005 - Accepted: 20 December 2005 - Published: 24 January 2006
}

\begin{abstract}
The HYDROPTIMET case studies 9-10/06/2000 Catalogne, 8-9/09/2002 Cévennes and 24-26/11/2002 Piémont encompass prototype flash-flood situations in the western Mediterranean, attending to the relevant synoptic and mesoscale signatures identified on the meteorological charts. A prominent mid-tropospheric trough or cut-off low can be identified in all events prior and during the period of heavy rains, which clearly served as the precursor agent for the onset of the flash-flood conditions and the cyclogenesis at low levels. Being aware of the uncertainty in the representation of the upper-level disturbance and the necessity to cope with it within the operational context when attempting to issue short to mid-range numerical weather predictions of these high impact weather events, a systematic exploration of the predictability of the three selected case studies, subject to uncertainties in the representation of the upper-level precursor disturbance, is carried out in this paper by means of numerical simulations.
\end{abstract}

\section{Introduction}

The core purpose of Interreg IIIB-Medocc HYDROPTIMET project (http://hydroptimet.medocc.org) was the improvement of the hydro-meteorological tools used in the western Mediterranean for the surveillance and prediction of flash floods.

Understanding the characteristic predictability of the flash-flood situations in the western Mediterranean appears as a basic task for assessing the value of incorporating the meteorological uncertainty in the prediction system (e.g. mesoscale ensemble forecasting systems). Some studies have shown a relative insensitivity of mesoscale model results to the precise structure of initial and boundary conditions in areas with complex terrain (e.g. Mass and Kuo, 1998). In the western Mediterranean region, the dynamical

Correspondence to: R. Romero

(Romu.Romero@uib.es) control of the heavy precipitation episodes is typically exerted by the interaction of the moist low-level wind, such as a low-level jet (LLJ) possessing a long fetch over the sea, with the coastal mountain systems (e.g. Doswell et al., 1998; Romero, 2001).

Interestingly, the HYDROPTIMET case studies comprise different geographical zones (Catalogne, southern France and Piémont areas) and, still more important, were regulated by both synoptic-scale and mesoscale disturbances depending on the case. Thus, the selected events become an ideal set of situations to investigate the predictability issue as a function of the spatial scale of the responsible circulation.

\section{Methodology and control simulations}

One way of examining the predictability of a meteorological patterns by means of a numerical model consists of perturbing the model initial conditions and display the spread of the model forecasts, including as reference some control or standard forecast. Assuming that the model is "perfect", we emphasize that the major source of uncertainty in realtime forecasting is associated with a deficient knowledge of the initial conditions ingested in the mesoscale model, because of insufficient observational data (a real problem in the data void Mediterranean latitudes) and/or an imperfect lower-resolution model forecast to construct the initial conditions. Our study, therefore, is based on an ensemble of mesoscale numerical simulations of each event with the MM5 non-hydrostatic model, after perturbing in a systematic way the upper-level precursor disturbance in the sense of displacing slightly this disturbance upstream/downstream along the zonal direction and intensifying/weakening its amplitude. Since these perturbations, expressed in terms of potential vorticity (PV), will be arbitrarily defined without regard to the actual climatology of analysis error variance of the PV field, our experiments will provide a sensitivity analysis of the selected events rather than a test of operational ensemble generation techniques. 
The perturbations are introduced to the initial conditions by first applying a piecewise potential vorticity inversion procedure to the positive PV anomaly associated with the upperlevel disturbance and then, the inverted fields (wind, temperature and geopotential) are used to modify under a physically consistent balance (Hoskins et al., 1985) the model initial fields. These perturbations are supported by a previous application of the MM5 Adjoint model, which consistently shows high sensitivities of the dynamical control of the heavy rain to the flow configuration about of the upper-level disturbance on the day before.

\subsection{MM5 model and control simulations}

The numerical experiments were performed using the fifth generation of the Pennsylvania State University-National Center for Atmospheric Research mesoscale model (MM5; Dudhia, 1993; Grell et al., 1995). MM5 is a full nonhydrostatic model formulated using the terrain-followingsigma-coordinate $(\sigma)$ system in the vertical. The multi-nest capability of the model with two-way interaction between successive nesting levels was used in order to get realistic terrain features and explicit representation of mesoscale processes (Zhang et al., 1986).

For the present simulations, two interacting domains under a Lambert Conformal map projection were used, both of them with $82 \times 82 \times 24$ grid points. The coarse domain measures $4374 \times 4374 \mathrm{~km}$ (grid length $54 \mathrm{~km}$ ) and the fine domain measures $1458 \times 1458 \mathrm{~km}$ (grid length $18 \mathrm{~km}$ ). Both domains are centred at the region affected by the flash floods. The first one is defined in order to describe the evolution of the synoptic pattern, highlight the upper-level precursor trough identified in all events and characterize its sensitivities areas and its primary influence in the configuration of the low-level flow. The fine domain is used to capture the most important mesoscale aspects of the episodes, which leaded to the damaging heavy rains. Global analyses on standard pressure surfaces from NCEP for Catalogne and Cévennes events (available at 00:00 and 12:00 UTC with $2.5^{\circ}$ horizontal resolution) and from ECMWF for Piémont-I and PiémontII (at 00:00, 06:00, 12:00 and 18:00 UTC with 0.3 resolution), were used to nest the mesoscale model. Simulations extend $36 \mathrm{~h}$ for Catalogne (from 00:00 UTC 9 June 2000 to 12:00 UTC 10 June 2000), $54 \mathrm{~h}$ for Cévennes (00:00 UTC 8 September 2002-06:00 UTC 10 September 2002), 36 h for Piémont-I (00:00 UTC 24 November 2002-12:00 UTC 25 November 2002), and $36 \mathrm{~h}$ for Piémont-II (00:00 UTC 25 November 2002-12:00 UTC 26 November 2002). Results of the control simulations are summarized below (more detailed information can be found in Romero et al., 2005).

\subsubsection{Catalogne event}

This episode developed under a synoptic pattern characterized by an Atlantic cold upper-level trough progressing from western Europe and a low sea-level pressure area along the British Islands, west France and Spain, with an associ- ated cold front extending south, down to north Africa (see Fig. 1a). In response to the strong vorticity advection occurring aloft over eastern Spain as the intense trough entered the Iberian Peninsula, a secondary low developed offshore the eastern coast of Spain (see Fig. 2a). The cyclonic moist flow established on the western Mediterranean impinged the north-eastern Spanish littoral and provided a continuous supply of warm and moist air toward the Catalan coast. This mesolow exerted a major control of the flash floods. As is shown in Fig. 2a, the combined action of three distinct airstreams enhanced the low-level convergence in Catalonia and leaded to a convectively unstable environment: the warm and moist south-easterly flow induced by the lowlevel mesoscale size cyclone, a cold flow turning anticyclonically around the eastern flank of the Pyrenees and the northwesterly winds associated with the approaching cold front at low-mid levels. It can be concluded that MM5 model simulates accurately the synoptic and mesoscale processes since the forecast rainfall (see Fig. 2a; maximum value of $165 \mathrm{~mm}$ ) is reasonably good, both spatially and quantitatively (compare with Fig. 3a).

\subsubsection{Cévennes event}

The synoptic setting of the Cévennes case was characterized by a large-scale trough at mid-upper tropospheric levels located during the full episode over the Atlantic ocean (see Fig. 1b). The resulting surface cyclone was much larger than in the previous event (synoptic scale vs. mesoscale dimensions) and located over the Atlantic, far from the affected area. However, it provided the essential component for the genesis and maintenance of the quasistationary convective system that affected the Cévennes region: a southerly lowlevel jet over the western Mediterranean impinging on the topography of southern France. A key feature of the episode was the relative stagnancy of the synoptic situation, which allowed a long persistence of the LLJ and therefore, the generation of convective instability and moisture flux convergence in the convective zone for a long time. This explains the long-lasting and quasistationary character of both the simulated and observed rainfall during the event. In Fig. 2b, it can be appreciated the notable role of the Alps mountains in the sense of enhancing along its western flank the LLJ as well as displacing the heavy precipitation centre (maximum value, $367 \mathrm{~mm}$ ) over inland mountain slopes, some tenths of $\mathrm{km}$ north of the observed location (Fig. 3b).

\subsubsection{Piémont-I event}

This episode was also linked to an upper-level system of long wavelength with the trough located over the Atlantic ocean (see Fig. 1c) but, unlike Cévennes, the trough maintained an open wave pattern and the accompanying PV anomaly did not become isolated from the high-latitude reservoir. At low levels, the circulation was regulated by an extensive low-pressure area lying over the Atlantic, which induced a southerly LLJ with a long fetch over the 
(a)

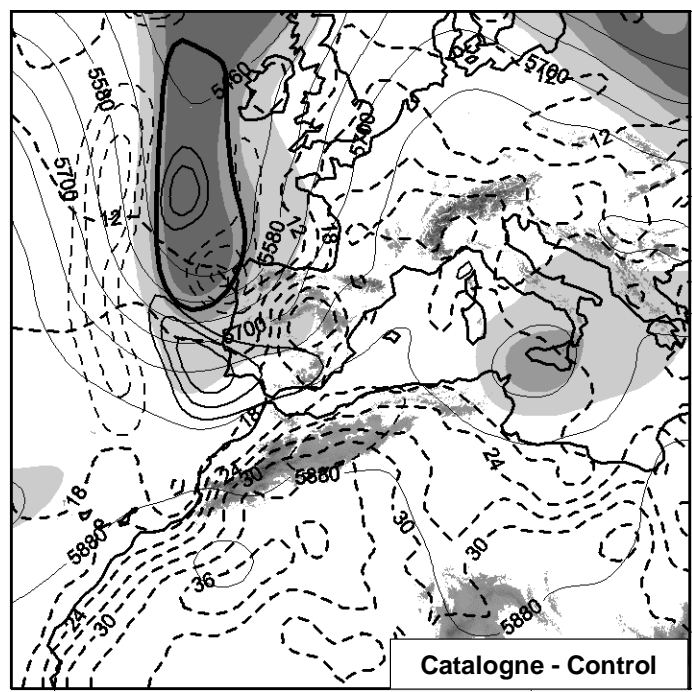

(c)

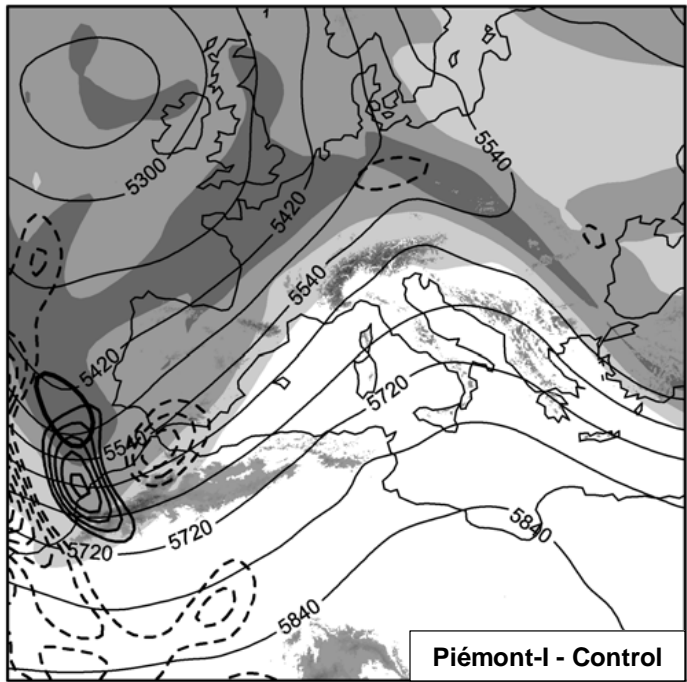

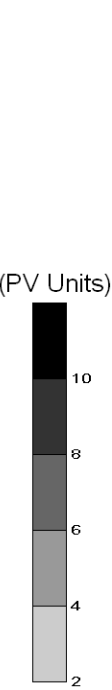

(d) (b)

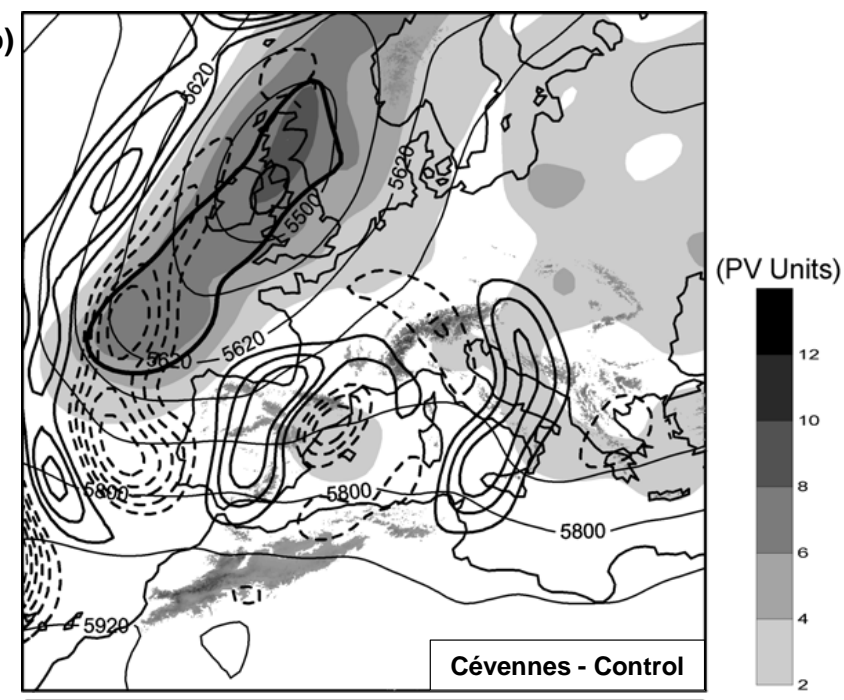

(d)

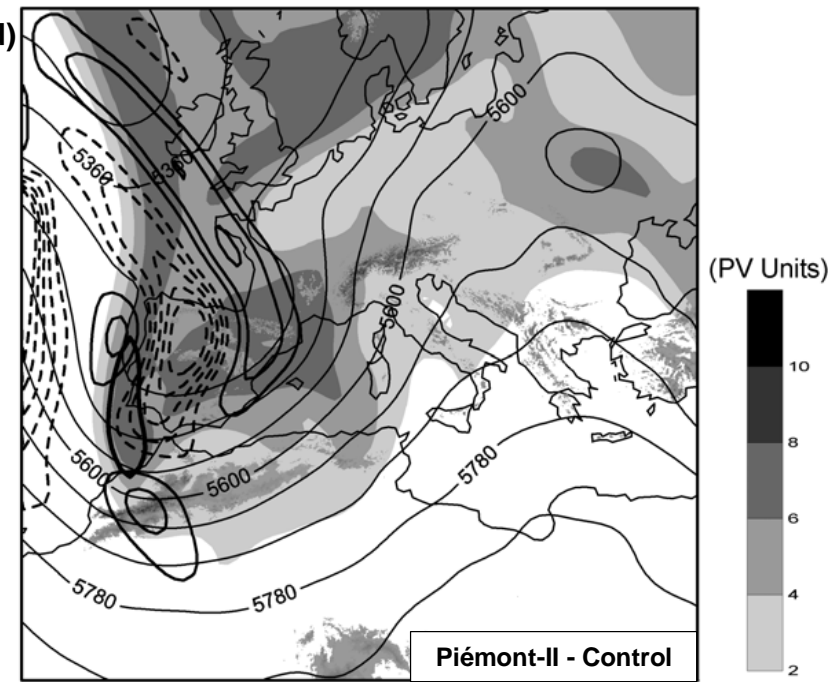

Fig. 1. Control simulation for the coarse domain, showing geopotential height at $500 \mathrm{hPa}$ (thin continuous line, in gpm), isentropic $\mathrm{PV}$ on the $330 \mathrm{~K}$ surface (shaded, according to scale), the PV anomaly that was inverted to construct the perturbed simulations at the same isentropic surface (thick continuous line) and the main areas of sensitivity also on the $330 \mathrm{~K}$ isentropic surface (mid-size continuous line, positive values; fine dashed line, negative values) for the selected response functions: (a) Catalogne event at 00:00 UTC on 9 June 2000. Here, it has also plotted the temperature at $925 \mathrm{hPa}$ (thick dashed line, in ${ }^{\circ} \mathrm{C}$ ); (b) Cévennes event at 00:00 UTC on 8 September 2002; (c) Piémont-I event at 00:00 UTC on 24 November 2002; and (d) Piémont-II event at 00:00 UTC on 25 November 2002. Main orographic systems are highlighted.

Mediterranean that impinged over the Alpine region. A secondary trough/cyclone above the Iberian Peninsula helped to enhance the LLJ towards the end of the period. A similar function than in the previous event can be attributed to this LLJ, in the sense of supplying moisture rich air from the Mediterranean into the affected area and forcing upward vertical motion through mechanical lifting over the slopes of the Alps and its foothills. These processes are well captured by MM5 model since the forecast rainfall (see Fig. 2c) reproduces many qualitative and quantitative aspects of the observed precipitation (see Fig. 3c). The precipitation forecast (maximum value, $157 \mathrm{~mm}$ ) is particularly good inland, over the slopes of the Alps, as a clear example of the predictability level added by the strong topographic forcing.

\subsubsection{Piémont-II event}

It is interesting the transition observed during the long Piémont episode toward its second phase. The upper-level trough intensified and advanced eastward into north Africa and the western Mediterranean (see Fig. 1d). As shown in Fig. 2d, the resulting cyclone at low levels can be classified as of mesoscale size, although it is much larger than the cyclone developed in the Catalogne event (compared with Fig. 2a). The meridionally elongated cyclone conditioned the direction and strength of the moist LLJ along its eastern flank. Again, the presence of the Alps was crucial for the rainfall forecast (maximum value, $223 \mathrm{~mm}$ ), precisely in the areas less directly affected by the Mediterranean cyclone. 
(a)

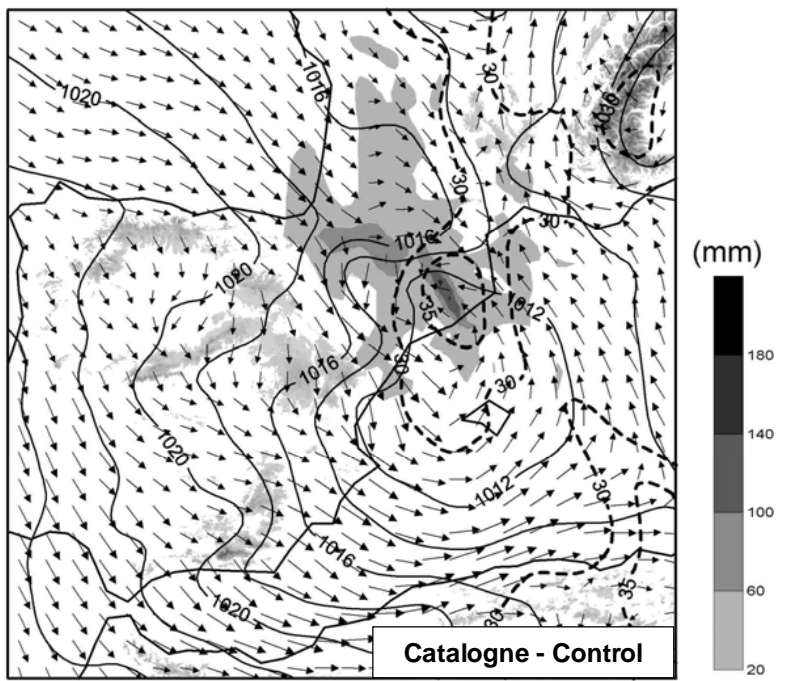

(c)

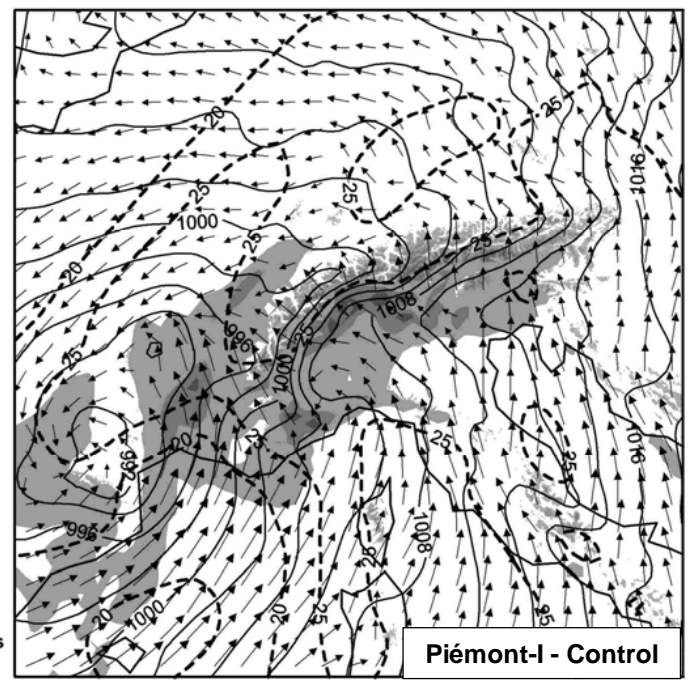

\author{
(b)
}
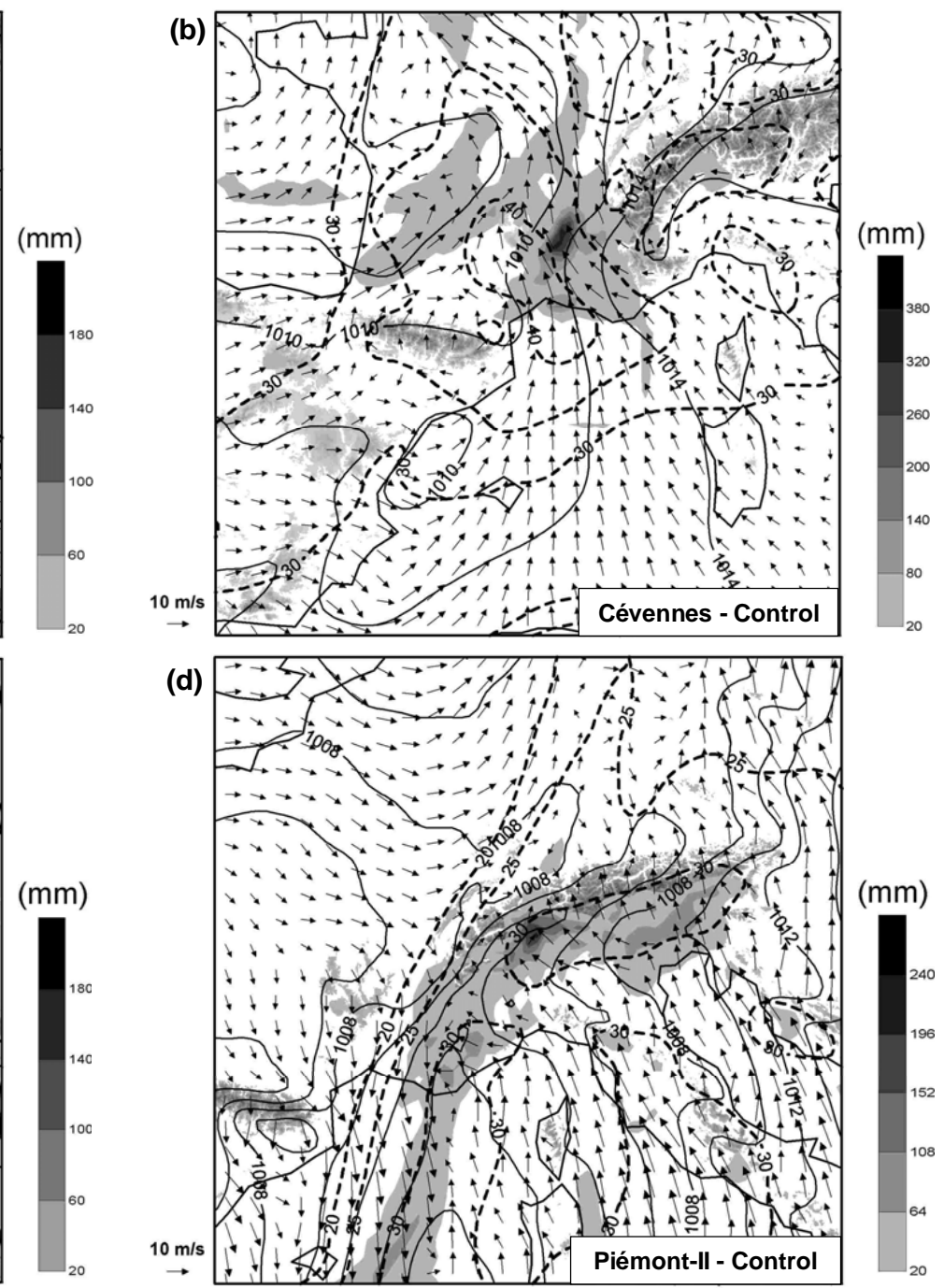

(d)

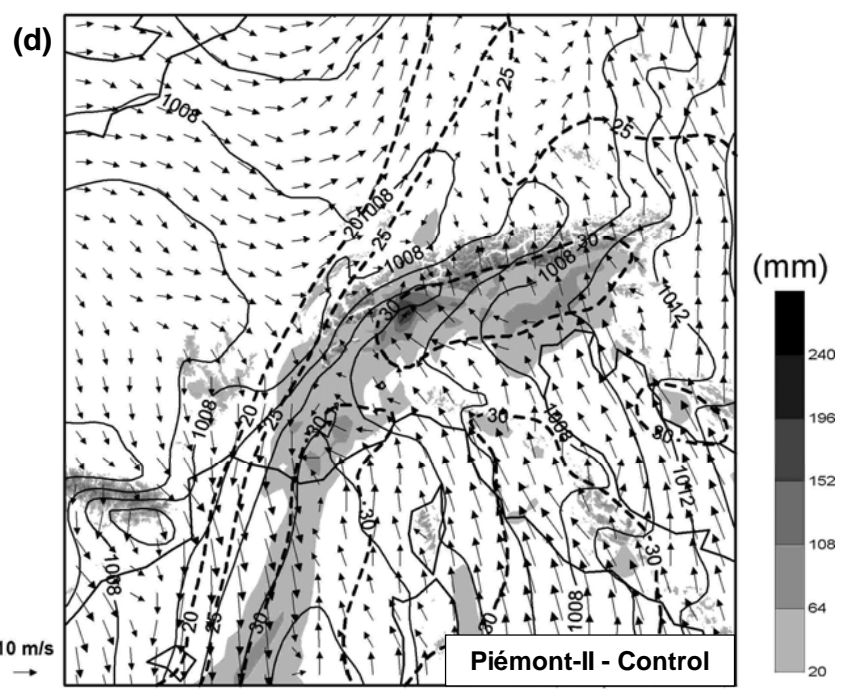

Fig. 2. Control simulation for the fine domain, showing sea level pressure (continuous line, in $\mathrm{hPa}$ ), precipitable water (dashed line, in mm) and horizontal wind at $950 \mathrm{hPa}$ (vectors) of each episode: (a) Catalogne at 00:00 UTC on 10 June 2000; (b) Cévennes at 00:00 UTC on 9 September 2002; (c) Piémont-I event at 00:00 UTC on 25 November 2002; and (d) Piémont-II event at 26 November 2002. Accumulated rainfall at the end of the simulations (shaded according to scale) is shown for the four events, with a maximum value of: (a) $165 \mathrm{~mm}$; (b) $367 \mathrm{~mm}$; (c) $157 \mathrm{~mm}$; and (d) $223 \mathrm{~mm}$. Main orographic systems are highlighted.

It is interesting to examine to which extent possible errors in the representation of the initial upper-level trough would affect the heavy precipitation forecast, owing to a deficient prediction of the surface cyclone characteristics. The control simulation appears to be appropriate attending to the good capability of the model to simulate many aspects of the observed precipitation field (compare with Fig. 3d).

\subsection{Piecewise PV inversion scheme}

The method used to investigate the sensitivity of the mesoscale simulations to changes in the upper-level precursor trough requires the calculation of a balanced flow associated with the trough-related PV anomaly at simulation start time. For that purpose the piecewise PV inversion technique of Davis and Emanuel (1991) was used. The method begins with the calculation of the total balance flow, described by $\Phi$ (geopotential) and $\psi$ (streamfunction), from the instantaneous distribution of Ertel's potential vorticity $(q)$, defined as:

$$
q=\frac{1}{\rho} \eta \cdot \nabla \theta,
$$

where $\rho$ is the density, $\eta$ the absolute vorticity vector and $\theta$ the potential temperature. Later, a reference state $(\bar{q}, \bar{\phi}$, $\bar{\psi})$, which is defined as a time average, is found and used to express to the flow anomalies $\left(q^{\prime}, \phi^{\prime}, \psi^{\prime}\right)$ :

$$
(q, \phi, \psi)=(\bar{q}, \bar{\phi}, \bar{\psi})+\left(q^{\prime}, \phi^{\prime}, \psi^{\prime}\right)
$$

The PV anomaly $q^{\prime}$ can be partitioned in $n$ anomalies of interest and the corresponding contributions to the flow 
(a)

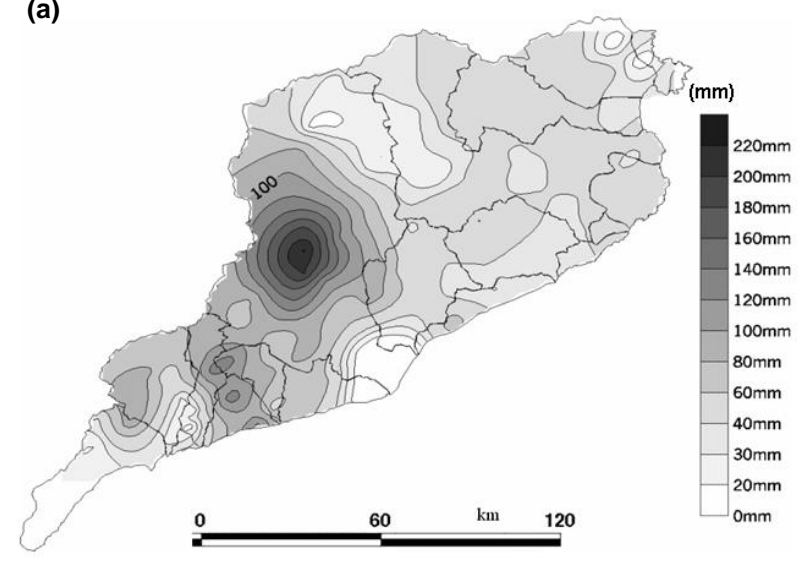

(c)

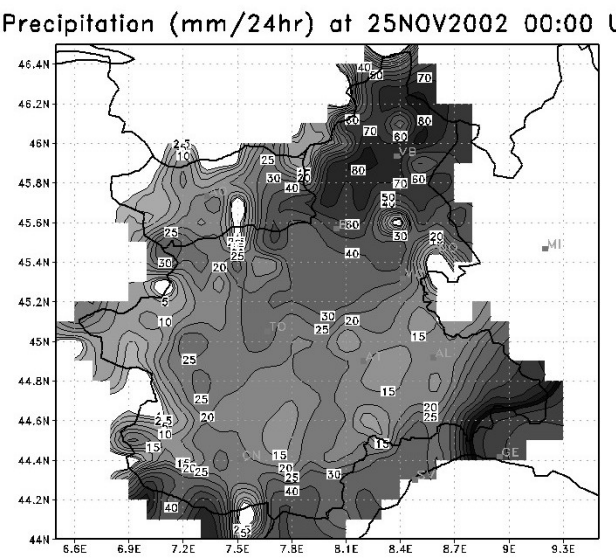

(b)

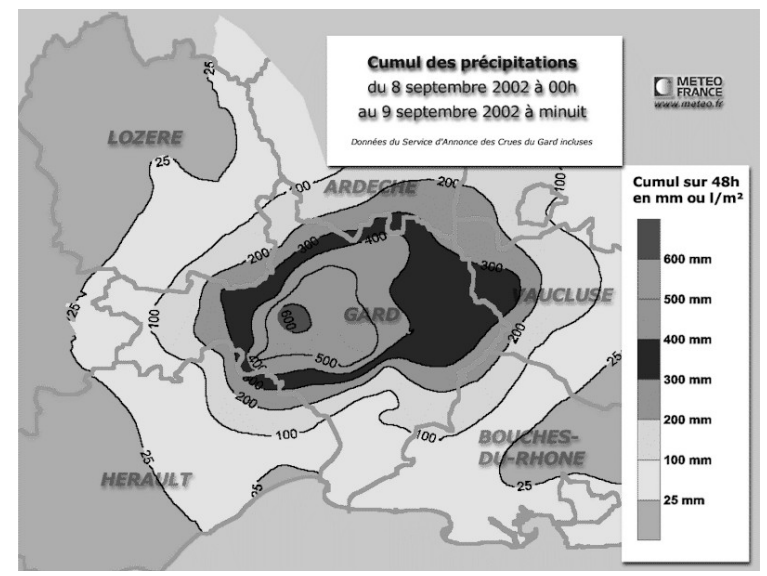

(d) Precipitation $(\mathrm{mm} / 24 \mathrm{hr})$ at 26NOV2002 00:00 UTC

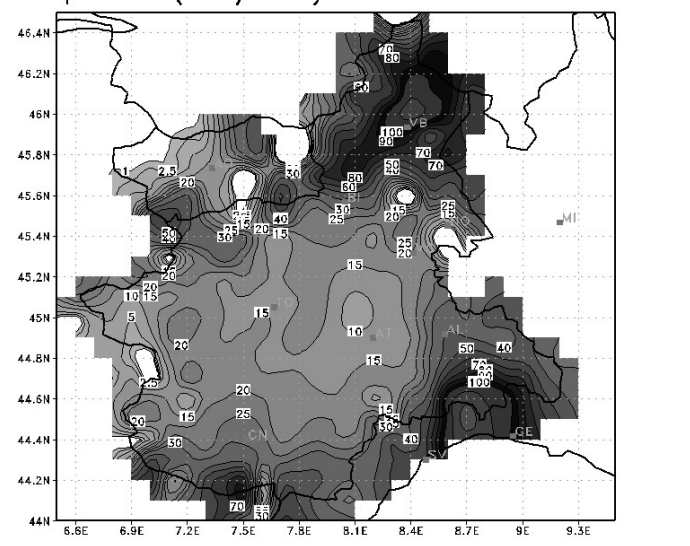

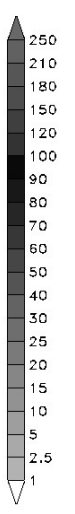

Fig. 3. Observed precipitation for the case studies according to scale: (a) Catalogne event from 00:00 UTC 9 June to 12:00 UTC 10 June 2000 (courtesy of M. C. Llasat); (b) Cévennes event during the period indicated in the figure (courtesy of Meteo France); (c) Piémont-I event during the period indicated in the figure (courtesy of M. Milelli); and (d) Piémont-II event during the period indicated in the figure (courtesy of M. Milelli).

calculated as described in Davis and Emanuel (1991). The induced flow anomalies can then be used to perturb the initial conditions as shown by Romero (2001). The piecewise PV inversion technique attributes components of the mass and wind fields to structures of the PV field. This allows exploring the impact of PV features in the initial conditions on the evolution of numerical simulations. Within this framework, a linear adjoint model is a powerful tool that can provide direct guidance about the PV features that are most likely influential for a particular aspect of interest in the forecast (Arbogast, 1998).

\subsection{Adjoint method and sensitivity fields}

A usual application of adjoint model is to compute sensitivities of forecast errors and detect regions in the initial conditions that are more likely responsible for the errors (e.g., Errico, 1997). We use the MM5 Adjoint model (Zou et al., 1997 and 1998) developed at NCAR, which has already been applied and tested for a Mediterranean intense cyclone by Homar and Stensrud (2004). Here, the results provide a guidance to define initial perturbations where the selected episodes analysed show large sensitivity and therefore, where small errors would lead to major errors in the forecast of the damaging rains, reducing its predictability. The sensitivity calculations are run on the mother domain of each control experiment. We provide the model a response function of interest at a certain sensitivity time and it traces back its sensitivity to the initial conditions fields. In its current version, MM5 Adjoint model code does not allow defining response functions based on other fields that are not the wind speed, temperature, pressure and specific humidity. Once provided this limitation in the model code and in order to obtain representative results, it is preferred to define response functions that characterize precursor dynamical systems clearly linked to the most interest feature in the forecast. 
(a)

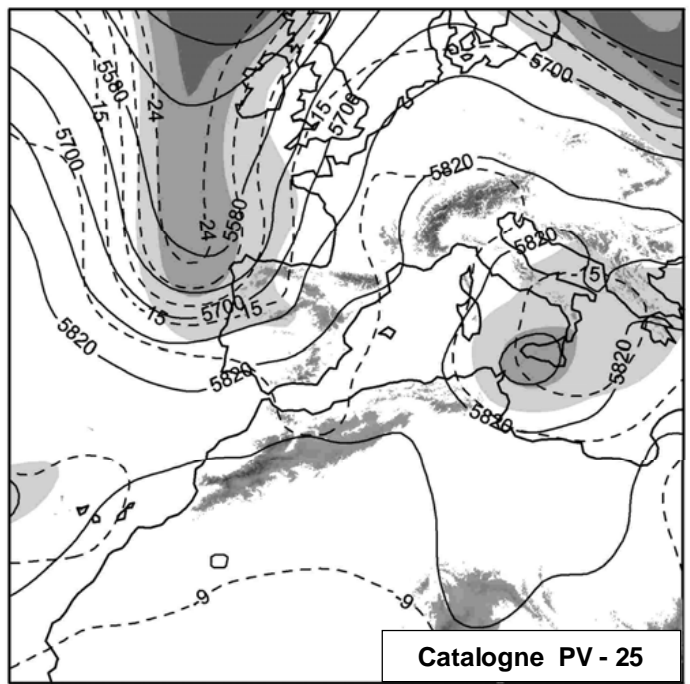

(c)

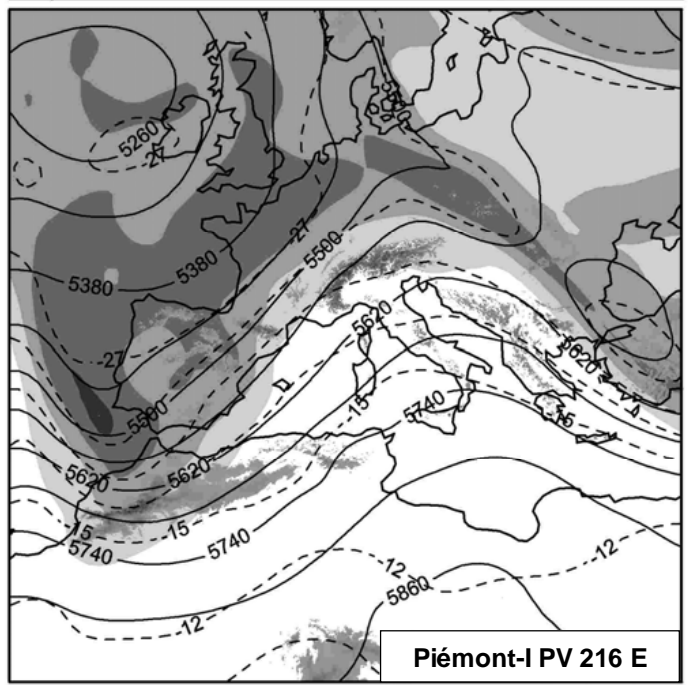

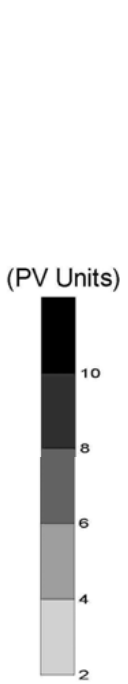

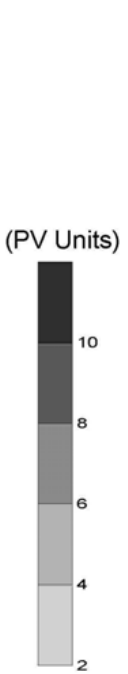

(b)

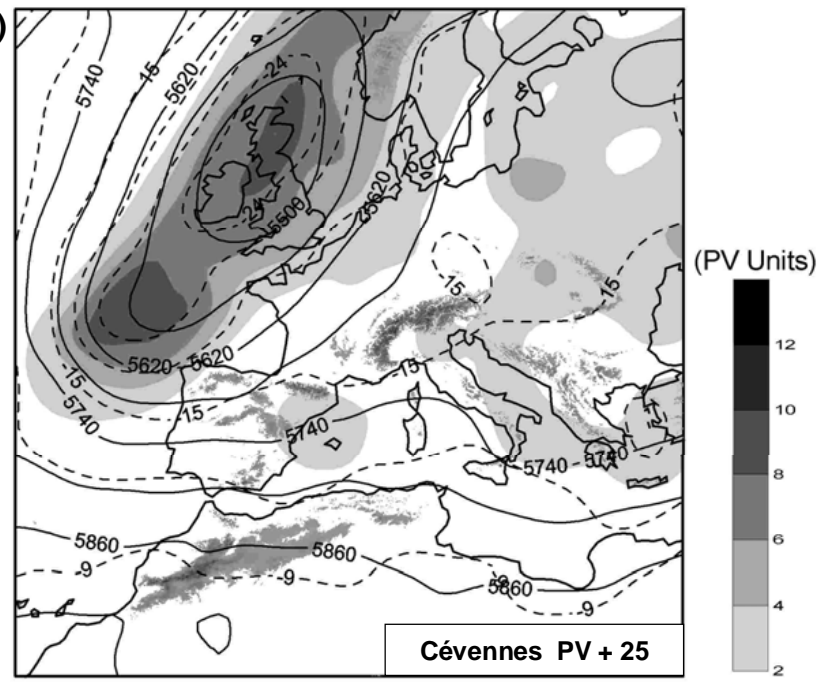

(d)

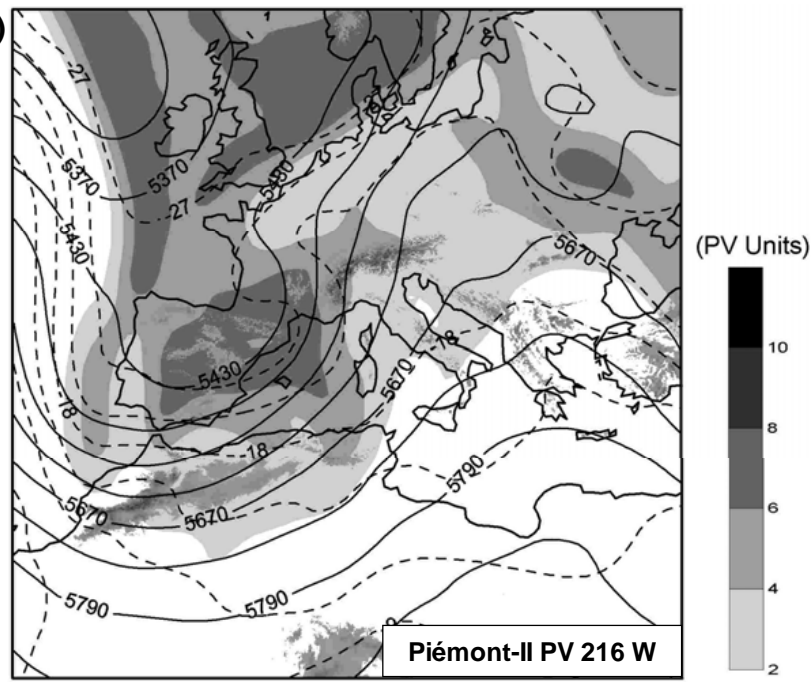

Fig. 4. Selected perturbed simulations for the coarse domain, showing geopotential height at $500 \mathrm{hPa}$ (continuous line, in gpm), temperature at $500 \mathrm{hPa}$ (dashed line, in ${ }^{\circ} \mathrm{C}$ ) and isentropic PV on the $330 \mathrm{~K}$ surface (shaded, according to scale) for the following experiments: (a) Catalogne PV -25; (b) Cévennes PV +25; (c) Piémont-I PV 216 E; and (d) Piémont-II PV 216 W. Main orographic systems are highlighted.

Therefore, defined response functions for each case characterize dynamical features previously identified to be involved in triggering and sustaining the heavy precipitation development. For the Catalogne case, it is the vorticity over the center of the low-level cyclone developed offshore northeastern Spain at 00:00 UTC 10 June 2000. In the Cévennes case the response function definition is based on the lowlevel wind (speed and direction) over the Gulf of Lyons and extending southeast, towards Sardinia at 06:00 UTC 9 September 2002. Finally, for the two active periods of the Piémont episode the response functions are defined as the low-level wind (speed and direction) on the eastern side of the cyclone at 06:00 UTC 25 November 2002 and the sea level pressure around the cyclone center at 06:00 UTC 26 November 2002, respectively. The adjoint model is then initialized with these response functions and their sensitivity to the corresponding initial conditions is computed (see the re- sults on Fig. 1). The Catalogne and Cévennes maps (Figs. 1a and $\mathrm{b}$ ) exhibit elongated distributions of PV, and the associated sensitivity patterns point primarily to their west and south sides. Both show areas with also notable sensitivity far to the east of the trough, over the western Mediterranean. Since these sensitivity structures are not related to intense PV features in the initial analysis, their physical interpretation is an indirect effect on the eastward progressing structures associated with the main trough. Regarding the Piémont-I and Piémont-II simulations, the distribution of high values is less confined and so the sensitivity fields exhibit also larger structures that are not focused on the regions of strong PV gradient. In summary, for all four sensitivity experiments, the adjoint results highlight various aspects of the precursor upper level trough, with special emphasis to its location and intensity. That is, the selected case studies show the largest sensitivity about the upper-level trough and, accordingly, the 

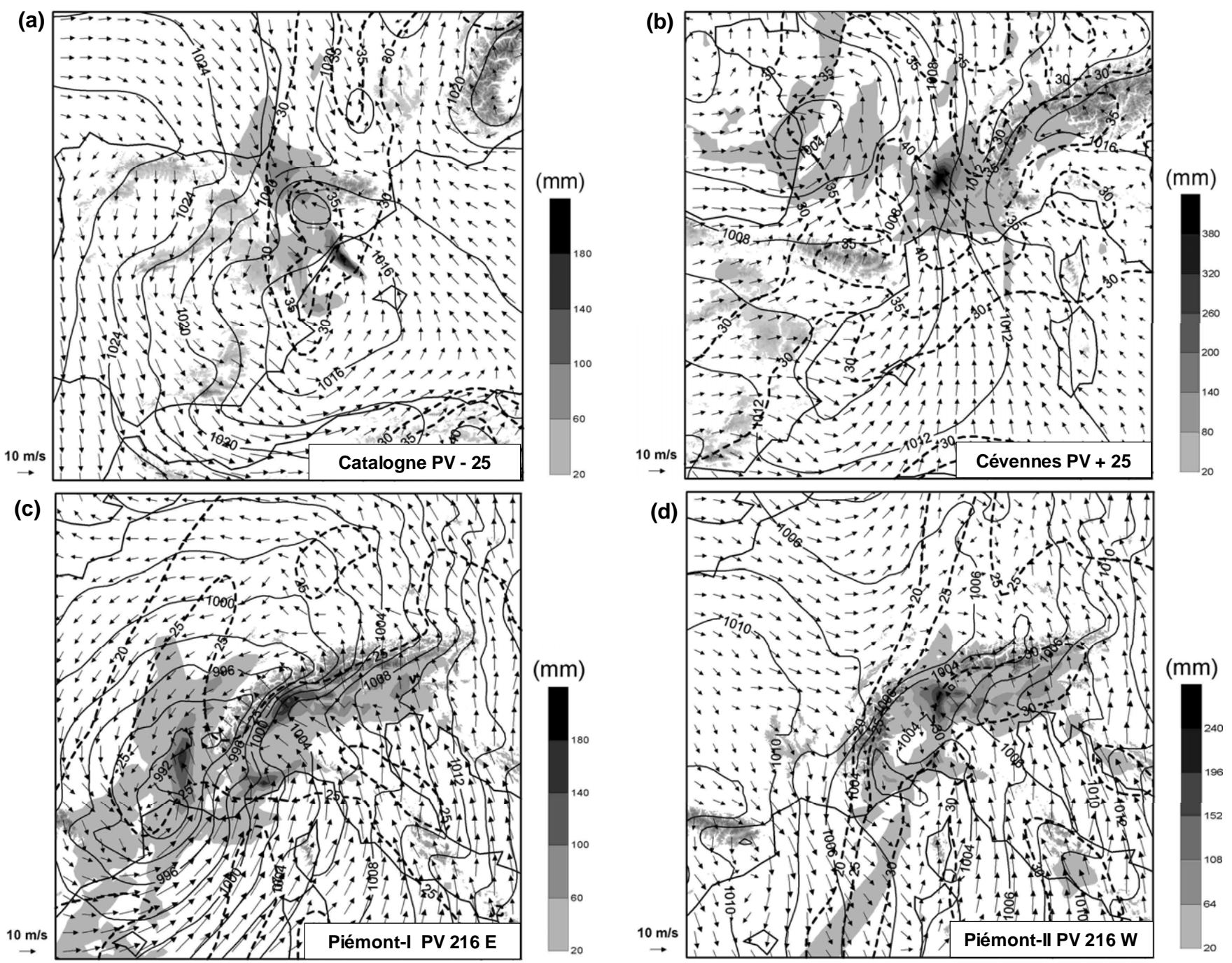

Fig. 5. Selected perturbed simulations for the fine domain, showing the same fields as in Fig. 2 for the following experiments: (a) Catalogne PV -25; (b) Cévennes PV +25; (c) Piémont-I PV 216E; and (d) Piémont-II PV 216 W. Maximum rainfall value is (a) $230 \mathrm{~mm}$, and (b) $438 \mathrm{~mm}$, and (c) $186 \mathrm{~mm}$, and (d) $240 \mathrm{~mm}$, respectively. Main orographic systems are highlighted.

PV anomalies highlighted in Fig. 1 (thick contour) were selected to construct the perturbed simulations.

\section{Results of the perturbed simulations and conclusions}

Provided that the small scale features of the PV field are more prone to analysis errors than the large scale components, the sensitivity study is focused on the initial intensity and position of the PV center embedded within the main cold trough. Table 1 summarizes the full set of simulations performed in the study following the piecewise PV inversion methodology. Main results are described below (more detailed information can be found in Romero et al., 2005):

\subsection{Catalogne event}

Since this episode was linked to a rapid and small-scale baroclinic cyclogenesis in response to the forcing imposed from upper-levels (recalls Figs. 1a and 2a), even small errors in the upper-level trough structure lead to appreciable changes in the spatial and quantitative details of the precipitation field. This has to be attributed to the mesoscale size of the Catalogne cyclone and the fact that a very specific flow is necessary for an effective interaction of the moisture-rich Mediterranean air with the topography of the region. Of particular significance is the result that a certain degree of stationary of the system is necessary to maintain the environmental ingredients in place for the heavy precipitations to occur: too fast or too distant cyclones simply result in much lower rainfall, whereas slow and near cyclones exhibit high precipitation potential. As an example of the latter, Figs. 4a and 5a 
Table 1. Summary of the numerical experiments performed for the four flash-flood events according to the methodology described in the text. Note that the upper-level trough is displaced $270 \mathrm{~km}$ for Cévennes and $216 \mathrm{~km}$ for the rest of events.

\begin{tabular}{lccccc}
\hline & \multicolumn{5}{c}{ Type of perturbation of the upper-level trough } \\
\hline Event & Unchanged & $\begin{array}{c}\text { Weakened } \\
25 \%\end{array}$ & $\begin{array}{c}\text { Intensified } \\
25 \%\end{array}$ & $\begin{array}{c}\text { Moved westward } \\
\text { 200-300 km }\end{array}$ & $\begin{array}{c}\text { Moved eastward } \\
\text { 200-300 km }\end{array}$ \\
\hline Catalogne & Control & PV -25 & PV +25 & PV 216 W & PV 216E \\
Cévennes & Control & PV -25 & PV +25 & PV 270 W & PV 270E \\
Piémont-I & Control & PV -25 & PV +25 & PV 216 W & PV 216E \\
Piémont-II & Control & PV -25 & PV +25 & PV 216W & PV 216E \\
\hline
\end{tabular}

show the results of the experiment in which the amplitude of the positive PV anomaly has been weakened by $25 \%$.

\subsection{Cévennes event}

It seems that the large scale nature of the precursor trough (see Figs. $1 \mathrm{~b}$ and $4 \mathrm{~b}$ ) tends to minimize the effects of the typical errors committed in the representation of the initial state. Despite some effects have been detected in the forecast rainfall of the Cévennes episode, especially in its quantitative aspects, these effects are unambiguously lower than in the previous Catalogne event for similar perturbations of the initial PV. The location of the general structure of heavy precipitation is particularly insensitive to the initial perturbations (e.g., Fig. 5b). Moreover, the action of the Alps range in enhancing the LLJ along its western flank and the role of the local topography in providing upward motion to the lowlevel moist parcels are dominant aspects which enhance the predictability of this kind of events.

\subsection{Piémont-I event}

This episode is another example of LLJ dominated flashflood event, a prototypic situation of the Alpine heavy precipitation phenomenology. Some resemblances to the Cévennes event are found for this case in regard to a moderate effect on quantitative precipitation but a very limited effect on its spatial distribution about the Alpine region. As opposite to the Cévennes event, a near cyclone played an important role being quite sensitive to the upper-level modifications (e.g., Fig. 4c), but since this cyclone was relatively large (compare with the Catalogne event) and the affected area lied to its east-northeast, even an appreciable error in the cyclone evolution along the Iberian Peninsula did not really affect the Mediterranean LLJ responsible for the heavy precipitations over the topographically complex Piémont area (see Fig. 5c).

\subsection{Piémont-II event}

Regarding the cyclone position and structure, the greatest changes with respect to the control attributes are found for the PV 216W experiment in which the positive PV anomaly has been displaced $216 \mathrm{~km}$ westward along its zonal direction (see Fig. 4d). Much higher sensitivities to the cyclone properties are found over the sea and coastal areas, where the topographical influence is weak or absent, than over inland mountainous zones. This fact basically illustrates that the former areas are directly affected by the cyclone itself and, therefore, changes in its evolution and structure affect significantly the precipitation field. In contrast, the latter zones are more indirectly affected by the system while the topographical influences play a crucial role. Similarly to the Cévennes and Piémont-I events, quantitative precipitation forecasts over the topographic complex areas appears to be moderately sensitive to the precise features of the lowlevel circulation, while the spatial distribution are essentially insensitive as shown in Fig. 5d.

\subsection{Conclusions}

Numerical sensitivity experiments point out important aspects regarding the predictability of this kind of western Mediterranean flash-flood events. A rich variety of synoptic and mesoscale processes were identified among the HYDROPTIMET case studies. The well established idea that the predictability of heavy precipitations in many Mediterranean areas is favoured by the complex topography emerged repeatedly during the course of the study. The intensity, location and the circulation associated with the mesocyclone and low level jet are shown to be strongly influenced by the regional orography, which helps to generate and/or sustain the persistent moist mediterranean flow. The accuracy of the initial conditions is shown to be crucial in the development of the selected episodes. On the one hand, the location of the upper-level precursor PV anomaly modulates the position of the low-level mesocyclone and the genesis and persistence of the low-level jet in the forecast. On the other hand, the intensity of the precursor trough modifies the translational speed of the mesolow as well as the direction and strength of the maritime flow towards the coast line. The Alpine events are probably the best example of strong topographical influence in action. A dominant role of the topography guarantees a reasonably correct spatial localization of the heavy precipitation areas in most of the situations, particularly under environmental settings governed by the large-scale dynamics rather than by mesoscale pressure systems. In contrast, the notion that accurate quantitative forecasts are also favoured 
by the complex topography is not as obvious. We found that the quantitative values can be significantly sensitive to the uncertainties of the upper-level trough and the associated low-level flow system.

The results generally show that the events dominated by mesoscale low-level disturbances (Catalogne and last stage of the Piémont episode) are very sensitive to the initial uncertainties, such that the heavy rain location and magnitude are in some of the experiments strongly changed in response to the 'forecast errors' of the cyclone trajectory, intensity, shape and translational speed. In contrast, the other situations (Cévennes and initial stage of the Piémont episode), dominated by a larger scale system which basically acts to guarantee the establishment and persistence of the southerly LLJ towards the southern France-north Italy orography, exhibit much lower sensitivity. That is, the slight modifications in the LLJ direction and intensity encompassed by the ensemble of perturbed forecasts are less critical with respect to the heavy precipitation potential and affected area.

Acknowledgements. This research was developed under the objectives and financial support of Spanish project MEDEXIB (REN2002-03482/CLI) and Interreg IIIB-Medocc European project HYDROPTIMET (2002-02-4.3-I-079). NCAR/Scientific Computer Division (sponsored by the National Science Foundation) and the Instituto Nacional de Meteorología (INM) of Spain are acknowledged for providing access to NCEP and ECMWF analyses, respectively.

Edited by: V. Kotroni and K. Lagouvardos Reviewed by: anonymous referee

\section{References}

Arbogast, P.: Sensitivity to potential vorticity, Quart. J. Roy. Meteor. Soc., 124, 1605-1615, 1998.

Davis, C. A. and Emanuel, K. A.: Potential vorticity diagnosis of cyclogenesis, Mon. Rev., 119, 1929-1953, 1991.

Doswell III, C. A., Ramis, C., Romero, R., and Alonso, S.: A diagnostic study of three heavy precipitation episodes in the western Mediterranean region, Wea. Forecast., 13, 102-104, 1998.

Dudhia, J.: A nonhydrostatic version of the Penn State/NCAR mesoscale model: Validation tests and simulation of an Atlantic cyclone and cold front, Mon. Rev., 121, 1493-1513, 1993.

Errico, R. M.: What is an adjoint model?, Bull. Amer. Meteor. Soc., 78, 2577-2591, 1997.

Grell, G. A., Dudhia, J., and Stauffer, D. R.: A description of the fifth-generation of the Penn State/NCAR mesoscale model (MM5), NCAR Tech. Note NCAR/TN-398+STR, Boulder, USA, 1995.

Homar, V. and Stensrud, D. J.: Sensitivities of an intense Mediterranean cyclone: Analysis and validation, Quart. J. Roy. Meteor. Soc., 130, 2519-2540, 2004.

Hoskins, B. J., McIntyre, M. E., and Robertson, A. W.: On the use and significance of isentropic potential vorticity maps, Quart. J. Roy. Meteor. Soc., 111, 877-946, 1985.

Mass, C. F. and Kuo, Y. H.: Regional real-time numerical weather prediction: Current status and future potential, Bull, Amer. Meteor. Soc., 79, 253-263, 1998.

Romero, R.: Sensitivity of a heavy rain producing Western Mediterranean cyclone to embedded potential vorticity anomalies, Quart. J. Roy. Meteor. Soc., 127, 2559-2597, 2001.

Romero, R., Martín, A., Homar, V., Alonso, S., and Ramis, C.: Predictability of prototype flash flood events in the western Mediterranean under uncertainties of the precursor upper-level disturbance: The HYDROPTMET case studies, Nat. Hazards Earth Syst. Sci., 5, 505-525, 2005.

Zhang, D. L. and Fritsch, J. M.: Numerical simulations of the meso$\beta$ scale structure and evolution of the 1977 Johnstown flood. Part I: Model description and verification, J. Atmos. Sci., 43, 19131943, 1986.

Zou, X., Vandenberghe, F., Pondeca, M., and Kuo, Y.-H.: Introduction to adjoint techniques and the MM5 adjoint modelling system, NCAR Tech. Note NCAR/TN-435+IA, Boulder, USA, 1997.

Zou, X., Huang, W., and Xiao, Q.: A user's guide to the MM5 Adjoint Modelling System, NCAR Tech Note NCAR/TN-437+IA, Boulder, USA, 1998. 